Dossier: Poesía, armonía y conflictos: ayer y hoy

\title{
El papel de la literatura en la construcción de la paz en Portugal y España durante los siglos XIX, XX y XXI
}

\author{
Gabriel Magalhães \\ Universidad de Beira Interior, Portugal \\ gm@ubi.pt \\ https://orcid.org/0000-0001-5010-085X
}

Recibido: 1 de agosto de 2019

Aceptado: 20 de setiembre de 2019

Resumen: Este texto estudia cómo la literatura colaboró en la construcción de la paz en las sociedades portuguesa y española a lo largos de los siglos XIX, XX y $X X I$. Inicialmente se centra en un texto fundador de la literatura lusa, Os lusíadas, de 1572, que constituye un paradigma bélico. No obstante, también hay en esta epopeya deseos de amor. Autores posteriores como Camilo Pessanha, Jaime Cortesão o Fernando Pessoa realizarán la crítica de este modelo épico guerrero. Se contribuye así a una sociedad pacífica, en la actualidad la cuarta más segura del mundo según el Índice Global de la Paz. En el caso español, algunos escritores como Pérez Galdós hicieron un esfuerzo equivalente por la paz y la concordia, pero el prestigio de la guerra, de las situaciones de conflicto aún se mantiene en sus obras literarias y en la actual sociedad española.

Palabras clave: paz; literatura; Portugal; España; 1801-2019.

\section{The role of literature in the construction of peace in Portugal and Spain during the nineteenth, twentieth and twenty-first centuries}

Abstract: This text studies how literature has collaborated in the construction of peace in Portuguese and Spanish societies throughout the nineteenth, twentieth and twenty-first centuries. Initially it focuses on a founding text of Portuguese literature, Os lusíadas, of 1572, which constitutes a belligerent paradigm. However, there is also desires for love in this epic text. Later authors such as Camilo Pessanha, Jaime Cortesão and Fernando Pessoa will critique this epic aggressive model. This contributes to a peaceful society, currently the fourth safest in the

\section{(c) (i) (9) (2)}

La Revista Estudios es editada por la Universidad de Costa Rica y se distribuye bajo una Licencia Creative Commons Atribución-NoComercial-CompartirIgual 3.0 Costa Rica. Para más información envíe un mensaje a 


\section{Dossier: Poesía, armonía y conflictos: ayer y hoy}

world according to the Global Peace Index. In the Spanish case, some writers like Pérez Galdós made an equivalent effort for peace and harmony, but the social prestige of war, of conflict situations is still maintained in their literary works and in the current Spanish society.

Keywords: peace; literature; Portugal; Spain; 1801-2019.

En un trabajo anterior (Magalhães, 2014, pp. 17-25), hemos planteado que la idea muy extendida de que Portugal es un país de "brandos costumes" - de "costumbres suaves"- no corresponde a la verdad de su pasado histórico. De hecho, la cultura portuguesa fue desde la aparición política de la nación (siglo XII) claramente guerrera y, además, a partir de la expansión marítima, iniciada em 1415 con la conquista de Ceuta, también esclavista. No obstante, es cierto que, ante las catástrofes políticas y militares sucedidas en su propio territorio durante la primera mitad del siglo XIX, que incluyeron invasiones de tropas francesas (1807, 1809, 1810), una guerra civil (1832-34) y graves tumultos y conflictos sociales (1846-47), Portugal se lanzó en la construcción de la paz. Este proceso de edificación de una sociedad pacífica involucró a la política, a la ciudadanía en general, pero fue también, en gran medida, un combate y una conquista de la literatura portuguesa. Muchos escritores lusos se volcaron en este desiderátum y, después del trabajo de sucesivas generaciones, el mundo portugués vive hoy en día en paz. La célebre imagen de los claveles en los cañones de los fusiles, que es quizá el mayor símbolo de la revolución del 25 de abril de 1974 -y que representa el modo como el deseo de paz amordaza el poder nefasto de las armas-, constituye el corolario de toda esta construcción. Concluyendo este resumen de las investigaciones que hemos realizado en nuestro trabajo previo, no sería equivocado afirmar que la paz fue la gran conquista de los últimos 170 años de la historia portuguesa.

\section{(c) (i) (2)}

La Revista Estudios es editada por la Universidad de Costa Rica y se distribuye bajo una Licencia Creative Commons Atribución-NoComercial-CompartirIgual 3.0 Costa Rica. Para más información envíe un mensaje a 


\section{Dossier: Poesía, armonía y conflictos: ayer y hoy}

En este artículo alargaremos la indagación que hemos realizado, abriendo cuatro nuevas vías de investigación. En primer lugar, regresaremos al gran poema nacional, Os lusíadas, una obra de Luís de Camões publicada en 1572, para ver cómo en este texto fundamental se presenta el tema de la paz y de la guerra. Aunque este libro no se incluye en el periodo cronológico que nos interesa, los siglos $X I X, X X$ y $X X I$, se trata de una obra crucial que, por su importancia, ha tenido mucha influencia en la sociedad lusa. Además, las celebraciones del tercer centenario de la muerte del poeta, en 1880, fueron uno de los momentos más significativos de la vida cultural y política del Portugal decimonónico, como explica Fernando Castelo-Branco (citado en Gomes et al., 1986, p. 265). De esta forma, Os lusíadas adquirieron una presencia muy actuante en la cultura portuguesa de este siglo. En segundo lugar, intentaremos comprender cómo Camilo Pessanha, un importante poeta simbolista luso, participó en este proceso. A continuación, en tercer lugar, nos interesaremos por una importante obra publicada sobre de la participación de Portugal en la Primera Guerra Mundial (1914-18), algo que ocurrió en los años de 1916 y 1918 (de hecho, el país no entró en este conflicto al inicio de la guerra, sino ya en su segunda mitad). Finalmente, en cuarto lugar, y esto será una coda de nuestro trabajo, veremos si, en el ámbito de la literatura española, también podemos encontrar esta pugna literaria por la paz.

El regreso a Os lusíadas confirma, sin duda, el ADN guerrero de la cultura portuguesa. Todo empieza por el primer verso, "As armas e os barões assinalados" (I, 1, 1)', un conocido homenaje al "Arma virumque cano" de Virgilio. En este incipit, además de la erudita cita literaria latina, propia de ese hombre del renacimiento y del manierismo que fue Luís de Camões, vive también la idea de que las armas caracterizan a los hombres, les dan relieve, verdad, grandeza. Los grandes héroes de la historia portuguesa serán, pues, guerreros. El acero del armamento constituye, de este modo, un espejo en el que la nación se ve a sí misma. Portugal es un país que se define como un catálogo de batallas.

La Revista Estudios es editada por la Universidad de Costa Rica y se distribuye bajo una Licencia Creative Commons Atribución-NoComercial-Compartirlgual 3.0 Costa Rica. Para más información envíe un mensaje a revistaestudios.eeg@ucr.ac.cr. 


\section{Dossier: Poesía, armonía y conflictos: ayer y hoy}

Llaman también la atención los adjetivos que, a lo largo del texto, el poeta elige para caracterizar el pueblo luso. Se trata de "gente fortíssima" (II, 75, 4), que constituye el "belicoso Reino Lusitano" (III, 26, 8). Los portugueses aparecen asociados al romano Marte, como si este fuera para ellos un modelo, una inspiración. De hecho, hay dimensiones del dios de la guerra que son propias de Portugal: existe, de esta forma, "o Mavorte feroz dos Portugueses" (VI, 58, 6). En este análisis lexical quizá lo que más impacta sea la palabra "horrendo" como calificativo de lo portugués. Hoy en día, pocos lusos se sentirían definidos por este adjetivo asustador. Pero no cabe ninguna duda de que, en la epopeya de Camões, esta palabra tan brutal funciona como una seña de identidad nacional: "Luso horrendo" (II, 48, 8), "peito lusitano, fero y horrendo" (II, 50, 6) son sintagmas muy claros en lo que concierne a esta cuestión.

Existe un momento de la obra que es particularmente diáfano a la hora de presentar la guerra como marca identitaria portuguesa. En el canto tercero de la epopeya, Vasco da Gama, el capitán de la armada que se dirige a la India por vía marítima, debe explicar Portugal al rey de Melinde, una monarquía de la costa oriental africana que se ha revelado aliada de los portugueses. Surgen entonces dos versos que son una introducción o un índice de la reflexión sobre cuestiones portuguesas que ocupará este canto y los siguientes, hasta el final del canto V: "Primeiro tratarei da larga terra,/Despois direi da sanguinosa guerra" (III, 5, 7-8). La cultura portuguesa se resume, pues, a la geografía, la "larga terra", y a la historia, que no es sino una "sanguinosa guerra", una guerra sangrienta. Por consiguiente, el viaje de Vasco da Gama a la India, periplo que constituye el tema de esta obra de Camões, un viaje que se concluyó con éxito en 1498, constituye la cúspide de una historia de violencia.

De hecho, esta importancia de la guerra en la epopeya del poeta luso ha sido detectada por muchos especialistas. Como afirma António José Saraiva (1995),

\section{(c) (i) (2)}

La Revista Estudios es editada por la Universidad de Costa Rica y se distribuye bajo una Licencia Creative Commons Atribución-NoComercial-CompartirIgual 3.0 Costa Rica. Para más información envíe un mensaje a 


\section{Dossier: Poesía, armonía y conflictos: ayer y hoy}

"quem lê Os Lusíadas encontra só o elogio dos cavaleiros e o enaltecimento dos feitos militares." (p. 137) Otros críticos subrayan que el espíritu bélico no sólo caracteriza el pasado, sino que será la argamasa con la que, para el poeta portugués, se construirá el porvenir. Según José Filgueira Valverde (1982), la epopeya de Camões tiene una lógica "suasória", o sea, persuasiva, intentando plantear la cruzada africana, un proyecto bélico más, como el futuro correcto para Portugal y para su rey, D. Sebastião (pp. 200-204). Como afirma este camonista gallego:

Porque tudo conflui para o futuro governo do jovem Rei e, concretamente, para o problema da Cruzada africana, que desde a abertura do poema e aparecendo nos momentos culminantes, se apresenta como o futuro histórico imediato, como o destino de Os Lusíadas. (p. 202)

Figueira Valverde no está solo en esta visión del texto. También Ramalho (1992), en esta misma línea, afirma que "para o futuro, o português [Luís de Camões] tem como projecto para o seu Rei e para a sua Pátria, a política africana" (p. 98). Y este crítico añade (p. 105):

Ora, se é verdade que Camões começa e acaba Os Lusíadas pelo incitamento à guerra no Norte de África, assim se incluindo entre os que teriam contribuído para o desastre do jovem soberano, não é menos verdade que todos os que exortavam o Rei a tal política não esperavam vê-lo passar às areias de África em pessoa.

Por consiguiente, no hay ninguna duda en lo que respecta al talante bélico de este texto, obra mayor de la literatura portuguesa; un empuje heroico y militarista que late en sus célebres octavas reales, formadas por ocho endecasílabos que, en su inmensa mayoría, tienen el aliento heroico de la acentuación en la sexta y en la

\section{(c) (i) (2)}

La Revista Estudios es editada por la Universidad de Costa Rica y se distribuye bajo una Licencia Creative Commons Atribución-NoComercial-CompartirIgual 3.0 Costa Rica. Para más información envíe un mensaje a revistaestudios.eeg@ucr.ac.cr. 


\section{Dossier: Poesía, armonía y conflictos: ayer y hoy}

décima sílabas. Aunque esta constatación sea incómoda para la cultura portuguesa actual, tan pacífica, es una verdad insoslayable que Os lusíadas se afirman como un texto belicoso, a veces "horrendo" en su amor por la guerra.

No obstante, también es cierto que, en una obra tan militarista, tan combativa, pulsa un secreto y paradójico deseo de paz. Este boceto de autocrítica de la epopeya de Camões se perfila sobre todo en tres elementos clave del texto. El primero se constata en el célebre episodio de Inés de Castro, que surge al final del canto III (118-138): esta mujer fue la amante de un príncipe, el futuro rey portugués D. Pedro, y acabó asesinada por el también rey portugués D. Afonso IV, padre del anterior, y sus consejeros, únicamente por consideraciones políticas. El episodio resulta conmovedor. Las armas del primer verso de la obra, que eran espejos de heroísmo, se transforman ahora en puro reflejo del horror. Es como si Camões dijera que el espíritu bélico, que el poeta suele ensalzar, debe a veces reportarse, debe imponer a sí mismo límites que no es lícito rebasar. Como se interroga el poeta (III, 123, 5-8): "Que furor consentiu que a espada fina,/Que pôde sustentar o grande peso/Do furor Mauro, fosse alevantada/Contra hua fraca dama delicada?"

Por lo tanto, el poeta reconoce que el espíritu bélico no es un valor absoluto. Más aún, en su epopeya, podemos reconocer dos energías: la de la guerra y la del amor. Parecen casi, incluso, dos pulsiones contradictorias que estructuran la tensión estética de Os lusíadas. Alguien como Oliveira Martins, uno de los grandes historiadores portugueses del siglo XIX, ya había detectado esta paradójica ternura en el gran poema nacional portugués. Según este crítico (1986, p. 47), “os homens de Camões só por momentos, excepcionalmente, aparecem animados pela fúria e pela força portuguesa”. De hecho, para Oliveira Martins, lo que sería clave, fundamental em Os lusíadas, es "o carácter meigo e bom do génio

\section{(c) (i) (2)}

La Revista Estudios es editada por la Universidad de Costa Rica y se distribuye bajo una Licencia Creative Commons Atribución-NoComercial-CompartirIgual 3.0 Costa Rica. Para más información envíe un mensaje a 
Dossier: Poesía, armonía y conflictos: ayer y hoy

português" (p. 46). No obstante, el historiador reconoce que el "Terror lusitano" ( $p$. 47) se encuentra claramente presente en el poema.

Por consiguiente, más allá de la vibración de la guerra, se perfila el deseo de amor. Un deseo que se cumple cabalmente cuando, en el canto IX, el penúltimo de la obra, los marineros desembarcan en la imaginaria Isla de los Amores, un lugar utópico, en el que recibirán la recompensa de su heroísmo, recompensa que se personifica en ninfas con las cuales cumplen sus fantasías eróticas y amorosas. Este momento de la epopeya contrasta poderosamente con los combates, los sangrientos relatos. Se confirma de este modo la idea de que existen dos pulsiones en este libro de 1572: el episodio de Inés de Castro y el canto IX, con su insularidad amante, comprueban que también el amor es un elemento matricial de Os lusíadas.

Un tercer elemento se añade a estas dos pruebas. En la obra, además del protagonista oficial, Vasco da Gama, jefe supremo de la armada, sólo dos marineros se destacan claramente del resto de la tripulación: uno es Veloso, que se revela sobre todo como alguien fuerte y feroz; el otro es Leonardo, que personifica al caballero enamorado. En la dualidad contrastada de estos dos personajes, creemos que se manifiesta también esta dualidad que hemos identificado em Os lusíadas: estamos, en resumen, ante una epopeya que, como no podía dejar de ser, ensalza, exalta la guerra, pero añorando el amor.

$\mathrm{Y}$ ahora podemos regresar a la época histórica que nos interesa, los siglos XIX, XX y XXI. A partir de 1851, de la instauración del régimen de la "regeneração", Portugal verá cómo, poco a poco, se cumplirá este sueño de amor, acabando con el terror de la guerra. En ese proceso, como hemos dicho, entran políticos, figuras culturales y también, en gran medida, la literatura. Importantes autores como Júlio Dinis o Eça de Queirós construyen narrativas que son propuestas de paz. Pero lo que sorprende es que incluso un bardo modernista como Camilo Pessanha (1867-

La Revista Estudios es editada por la Universidad de Costa Rica y se distribuye bajo una Licencia Creative Commons Atribución-NoComercial-Compartirlgual 3.0 Costa Rica. Para más información envíe un mensaje a 
Dossier: Poesía, armonía y conflictos: ayer y hoy

1926), alguien que desearía, según un célebre poema, "no chão sumir-se, como faz um verme..." (1995, p. 75) concreto, Pessanha entra en la cuestión de la paz y la guerra con el poema, sin título, que transcribimos a continuación (p.129):

Rufando, apressado,

E bamboleado,

Boné posto ao lado,

Garboso, o tambor

Avança em redor

Do campo de amor...

Com força, soldado!

A passo dobrado!

Bem bamboleado!

Amores te bafejem.

Que as moças te beijem.

Que os moços te invejem.

Mas ai, ó soldado!

Ó triste alienado!

Por mais exaltado

Que o toque reclame,

Ninguém que te chame...

Ninguém que te ame...

La Revista Estudios es editada por la Universidad de Costa Rica y se distribuye bajo una Licencia Creative Commons Atribución-NoComercial-CompartirIgual 3.0 Costa Rica. Para más información envíe un mensaje a revistaestudios.eeg@ucr.ac.cr. 


\section{Dossier: Poesía, armonía y conflictos: ayer y hoy}

De hecho, en este poema suena de inmediato la música modernista, una marcada sonoridad que, en estos versos, se concreta en el ritmo del tambor y en los ecos verbales de su acompasado ruido. Pero, una vez detectado este rasgo modernista de manual, surgen otros elementos no tan evidentes. Por ejemplo, en primer lugar, la métrica: estamos ante versos de siete sílabas. O sea, aproximadamente la mitad de un endecasílabo, el llamado "quebrado" de un endecasílabo. Una parte, pues, un fragmento, un residuo del verso heroico grandioso que Camões usó mayoritariamente en su obra Os lusíadas. Sabiendo nosotros que Pessanha cuidaba mucho las formas, sin duda este verso "amputado", por decirlo de alguna manera, funciona como una memoria residual del verso épico.

En realidad, este soldado constituye, precisamente, un fragmento, un resto de la grandiosa memoria épica portuguesa que se grabó, se consignó em Os lusíadas. Este espectro épico no sólo genera versos mermados, de siete sílabas, como además está solo. Existe el soldado, pero en ningún momento vemos un ejército. Los versos son restos, pero el propio soldado también lo es: representante final de un espíritu, de una actitud que está desapareciendo en la sociedad portuguesa. Esa soledad se acentúa dramáticamente en los últimos versos: "Ninguém que te chame.../Ninguém que te ame..." Nadie lo llama, nadie lo ama, y su exhibición de heroísmo, desfilando por la calle al ritmo del tambor, es en el fondo triste, lamentable. Toda la espectacular sonoridad del poema, concretada en gran parte en las rimas consonantes repetitivas, se encamina rumbo al silencio. Un silencio que es la inutilidad evidente, la soledad total de este soldadito, que más que representar la épica, escenifica la agonía del heroísmo: el final de un paradigma que marcó el pasado de la cultura portuguesa.

La edición crítica de la poesía de Camilo Pessanha, preparada por Paulo Franchetti, nos permite saber que la fecha que aparece en el manuscrito como siendo la de la transcripción de este poema es el día 15 de enero de 1916 (p.

\section{(c) (i) (2)}

La Revista Estudios es editada por la Universidad de Costa Rica y se distribuye bajo una Licencia Creative Commons Atribución-NoComercial-CompartirIgual 3.0 Costa Rica. Para más información envíe un mensaje a revistaestudios.eeg@ucr.ac.cr. 


\section{Dossier: Poesía, armonía y conflictos: ayer y hoy}

213). Este dato nos permite comprender mejor el texto. De hecho, en ese momento, en Europa suena el cañoneo furioso de la Primera Guerra Mundial y se vive el gran drama de la guerra de trincheras. Una guerra en la que este Portugal que se desea pacífico terminará involucrándose a partir de 1916. Esta participación lusa en el gran conflicto abrirá enormes heridas en la sociedad portuguesa y será una de las razones de la pérdida de popularidad del régimen republicano que había surgido en 1910. El poema de Pessanha se integra, pues, en una corriente que intentará expresar la inutilidad, el absurdo de la guerra. Una corriente de la que forma parte también el célebre poema de Pessoa "O menino da sua mãe" (Pessoa, 1981, vol. 1, p. 99), muy conocido en Portugal.

De hecho, la Primera Guerra Mundial, un paso atrás en el proyecto pacífico de la cultura portuguesa, terminó de destruir el paradigma épico. El soldado de Pessanha se silenció definitivamente. Muchos de los militares que partieron para las trincheras viajaron hacia allí con la memoria épica de Camões acariciándoles el corazón y volvieron transformados en la prosa atormentada del horror bélico, una experiencia atroz que los marcaría para siempre. Quizá el caso más impresionante sea el de Jaime Cortesão (1884-1960), alguien que, como diputado, votó la entrada de Portugal en la contienda mundial y, después, por coherencia ética, decidió alistarse como voluntario.

Cortesão escribirá la estremecedora obra Memórias da Grande Guerra (1919). Este libro admirable, poco conocido en Portugal, lo que constituye una enorme injusticia, puede ser definido como un auténtico antídoto contra Os lusíadas. En sus páginas estremecedoras, a veces brutales, casi siempre conmovedoras, se inscribió uno de los mayores manifiestos pacifistas de la cultura portuguesa. La guerra deja de ser una ilusión, una forma de excelencia. Una frase de absoluta sinceridad puede resumir toda la obra: "O soldado, que volta da guerra, é assim. Aí o têm. Conheceu algumas das mentiras militares e algumas das verdades

\section{(c) (i) (2)}

La Revista Estudios es editada por la Universidad de Costa Rica y se distribuye bajo una Licencia Creative Commons Atribución-NoComercial-CompartirIgual 3.0 Costa Rica. Para más información envíe un mensaje a revistaestudios.eeg@ucr.ac.cr. 


\section{Dossier: Poesía, armonía y conflictos: ayer y hoy}

essenciais na vida." (p. 256) La expresión "mentiras militares" suena a eufemismo: en realidad, se está hablando de mentiras épicas. De hecho, cuando llega a su término la Primera Guerra Mundial, el paradigma épico se ha agotado en la sociedad lusa. Pessoa, en su poema patriótico de 1934, Mensagem, no incluye la figura de Camões y, cuando habla de guerra, se refugia también en el eufemismo, como en los poemas que dedica al primer rey, D. Afonso Henriques, y sobre todo a D. Nuno Álvares Pereira, el gran héroe de la batalla de Aljubarrota (1385), un texto que citamos a continuación (Pessoa, 1979, p. 45):

Que auréola te cerca?

É a espada que, volteando,

Faz que o ar alto perca

Seu azul negro e brando.

Mas que espada é que, erguida,

Faz esse halo no céu?

É Excalibur, a ungida,

Que o Rei Artur te deu.

Esperança consumada,

S. Portugal em ser,

Ergue a luz da tua espada

Para a estrada se ver!

Las "armas" del incipit de Os lusíadas se resumen a una espada que, más que causa de muerte, es fuente de claridad, transformándose en "auréola", "halo", "luz". Una espada que se conecta con el paradigma mítico de la "Excalibur" del rey Arturo. No hay sangre, no hay muertos o víctimas. Se evitan, además, los espantosos adjetivos que usaba Camões: nada de "horrendos", nada de (c) (i) (2) (2)

La Revista Estudios es editada por la Universidad de Costa Rica y se distribuye bajo una Licencia Creative Commons Atribución-NoComercial-Compartirlgual 3.0 Costa Rica. Para más información envíe un mensaje a revistaestudios.eeg@ucr.ac.cr. 


\section{Dossier: Poesía, armonía y conflictos: ayer y hoy}

ferocidades. La guerra surge como dato simbólico y, por decirlo de alguna manera, edulcorado por el eufemismo.

La Primera Guerra Mundial, efectivamente, aumentará mucho la desconexión de la cultura portuguesa con el paradigma bélico. En realidad, la falta de capacidad de la Primera República para apuntalar la paz deseada provocará la aparición del Estado Novo (1933-1974), también llamado Segunda República, un régimen autoritario que evitó la entrada en la Segunda Guerra Mundial. Esa fue la gran hazaña política del dictador Oliveira Salazar: mantener la neutralidad durante la gran llamarada bélica de 1939-45. No obstante, también él se involucrará en una guerra, la colonial, que arrancará en 1961 y se desarrollará en varias de las posesiones portuguesas en África: Angola, Mozambique y Guinea Bissau. Ante este arrebato guerrero, la sociedad portuguesa se alejará gradualmente del salazarismo y del posterior régimen de Marcelo Caetano. Y, cuando estalla la revolución de 1974, la primera preocupación será restablecer la paz. Así se coronaron las armas, las viejas armas de nuestra historia, las que ya estaban en el primer verso de Os lusíadas, con pacíficos claveles. Hoy por hoy, en el Índice Global de la Paz, Portugal surge en cuarto lugar en la lista de países más tranquilos y sosegados del mundo, siendo superado sólo por Austria, Nueva Zelandia e Islandia (Institute for economics \& peace, 2018, pp. 8-9).

Llegamos, pues, a la coda de este ensayo: ¿existe en España, con un pasado guerrero muy intenso, en algunos aspectos semejante al portugués, una lucha por la paz que, a lo largo de los siglos XIX, XX y XXI, se haya concretado en textos literarios, textos que acompañaron $y$ acompañan procesos sociales de pacificación? De hecho, lo que encontramos en la realidad hispánica es el boceto de esto, pero no su realización plena. La crítica del paradigma guerrero ya se encuentra en la primera parte de El ingenioso hidalgo don Quijote de la Mancha, a través de la figura de un pobre y enajenado caballero andante. Pero, en esa

\section{(c) (i) (2)}

La Revista Estudios es editada por la Universidad de Costa Rica y se distribuye bajo una Licencia Creative Commons Atribución-NoComercial-CompartirIgual 3.0 Costa Rica. Para más información envíe un mensaje a 


\section{Dossier: Poesía, armonía y conflictos: ayer y hoy}

misma obra, en el discurso sobre las armas y sobre las letras, se valora de forma cuerda muy positivamente la actividad bélica (pp. 444-451) iii. Además, a través de la figura del cautivo, Cervantes, el "manco de Lepanto", considera esta última batalla como una ocasión extraordinaria: una "felicísima jornada" (p. 455).

Lo mismo pasa ya en pleno siglo XIX con la obra de Benito Pérez Galdós. Estamos ante un monumental trabajo por la paz y por la concordia. El novelista apunta errores de la sociedad hispánica: la intolerancia en Doña Perfecta (1876), el fanatismo religioso en Gloria (1876-77), la miseria social en Marianela (1878), el problema de la educación y del cambio de mentalidades en El amigo Manso (1882). Fortunata y Jacinta (1887), por otra parte, intenta plantear un gran acuerdo, un tratado de paz, entre el pueblo, personificado en Fortunata, y la burguesía aliada a la aristocracia, simbolizadas en Jacinta. Un acuerdo que no se alcanzó y ello fue sin duda uno de los motivos de la tragedia de la Guerra Civil (1936-39). No obstante, este mismo Pérez Galdós no resiste al encanto de la guerra en algunas de sus novelas de los Episodios nacionales, como es el caso, por ejemplo, de Trafalgar, la primera entrega de este amplio y ambicioso proyecto literario. Sin embargo, incluso en esta obra de marco tan bélico, tan enamorada de la hermosura de las batallas navales, que un personaje de la obra considera "cosa muy bonita" (p. 103), surgen retazos de un discurso que podemos considerar pacifista (pp. 186-187).

Existe otro ejemplo de la muy ambigua relación que la literatura española mantiene, en los siglos XIX, XX y XXI, con el fenómeno bélico. Después de la Guerra Civil, una de las grandes obras que se escribió sobre esta contienda fue la trilogía de José María Gironella, formada por Los cipreses creen en Dios (1953), Un millón de muertos (1961) y Ha estallado la paz (1966), a la cual se añadirá bastante más tarde un cuarto volumen: Los hombres lloran solos (1986). El primer tomo de la serie plantea la idea de que el conflicto fratricida fue una enorme

\section{(c) (i) (2)}

La Revista Estudios es editada por la Universidad de Costa Rica y se distribuye bajo una Licencia Creative Commons Atribución-NoComercial-CompartirIgual 3.0 Costa Rica. Para más información envíe un mensaje a revistaestudios.eeg@ucr.ac.cr. 


\section{Dossier: Poesía, armonía y conflictos: ayer y hoy}

tragedia: un abismo lentamente preparado en el que se precipitó la sociedad española. La muerte de César, un personaje de recorte hagiográfico, en las últimas páginas de Los cipreses creen en Dios (pp. 906-911) insinúa la idea de que la Guerra Civil consistió en un triunfo de todos los demonios, sociales, ideológicos y culturales. No obstante, en el segundo tomo, Un millón de muertos, la guerra, paradójicamente, surge con tonos a veces apasionantes. De ella se dice que es "un cuchillo de mil colores" (p. 280) y, al mismo tiempo, se reflexiona sobre la "magia" (p. 337) de la guerra. En Ha estallado la paz, el tercer trabajo de la serie, encontramos este diálogo entre Ignacio, uno de los grandes protagonistas de la obra, y Mateo, otra de las figuras clave de la novela, un diálogo muy transparente en lo que respecta a la relación contradictoria que estos libros y sus personajes mantienen con la gran contienda fratricida hispánica (p. 288):

- Ignacio, ¿te acuerdas mucho de nuestra guerra?

- Mucho. Más de lo que imaginé. Es como un telón de fondo. ¿No te ocurre a ti lo propio?

- ¡Hombre! Todavía no me he acostumbrado a no andar por los montes y a no llevar detrás de mí a un pelotón. ¡Era tan duro aquello! Y tan hermoso...

- ¿Hermoso? Eso habría que preguntárselo a los muertos.

- A los muertos también les pareció hermoso. Cayeron por un ideal. ¿No has oído al ex legionario?

- Lo he oído, claro. Pero él vive. Y los hubo que murieron tontamente, sin saber por qué.

- Nunca se muere sin saber por qué.

- No exageres, Mateo. El heroísmo no es ninguna obligación. ¿Cuándo te meterás eso en la cabeza?

- Nunca.

- Lo siento. Lo siento por ti... 
Dossier: Poesía, armonía y conflictos: ayer y hoy

- Ignacio..., ¿te acuerdas de cuando llegaste del frente? Hablabas de otro modo...

- Estaba borracho. Me había contagiado. Ahora lo que quiero es aprender.

- La guerra es una gran lección.

- A mí me parece que la gran lección es la paz. Y el Derecho Civil.

Como hemos dicho, toda la ambigüedad de la relación de la trilogía de Gironella con la guerra queda muy clara. La Guerra Civil es considerada, cariñosamente, como "nuestra guerra", a la cual Mateo concede rango de hermosura estética. Ignacio, no. No obstante, él mismo reconoce que hubo un tiempo en que se dejó arrastrar por la ebriedad bélica.

Esta misma ambigüedad respecto a la guerra, que se rechaza y que, al mismo tiempo nos atrae, se nota en la literatura actual, ya del siglo XXI. Existen obras claramente pacifistas como es el caso de la célebre novela Soldados de Salamina (2001), de Javier Cercas. Fernando Aramburu, con su Patria (2017), también intenta firmar un tratado de paz en lo que respecta al gran problema del terrorismo vasco y de las hondas heridas sociales que este creó. No obstante, alguien como Arturo Pérez Reverte, a través de la saga del capitán Alatriste, que empieza precisamente por una narrativa con el título El capitán Alatriste (1996), mantiene el magnetismo literario que la guerra, con toda su complejidad, genera, algo que también es visible, por ejemplo, en Cabo Trafalgar (2004), otra novela de este autor. En la sociedad española, la idea de conflicto, de confrontación, todavía mantiene una parte considerable de su prestigio.

Este es uno de los aspectos que más apuntala la identidad de la sociedad portuguesa en al actual panorama ibérico: de hecho, los descendientes de Camões han dicho adiós al modelo bélico, aunque sus colores, sus "mil colores", 
Dossier: Poesía, armonía y conflictos: ayer y hoy

puedan ser muy hermosos. Eso se refleja ya con mucha claridad en la vida cotidiana del país, sentido por propios y extraños como muy pacífico. Por el contrario, en el caso español, la relación con los paradigmas de confrontación sigue siendo ambigua: aunque ya no estamos ante una sociedad guerrera, la idea de que la lucha puede imponerse y ser absolutamente necesaria no se ha descartado. 


\section{Dossier: Poesía, armonía y conflictos: ayer y hoy}

\section{Referencias bibliográficas}

Aramburu, F. (2017). Patria. Barcelona, España: Tusquets.

Camões, L. de (versión 1978,1572). Os lusíadas, ed. de E. P. Ramos. Porto, Portugal: Porto Editora.

Cercas, J. (versión 2002, 2001). Soldados de Salamina. Barcelona, España: Tusquets.

Cervantes, M. de (versión 1982, 1605). El ingenioso hidalgo Don Quijote de la Mancha I, ed. de J. J. Allen. Madrid, España: Cátedra.

Cortesão, J. (versión 1969, 1919). Memórias da Grande Guerra. Lisboa, Portugal: Portugália.

Filgueira Valverde, J. (1982). Camões: Comemoração do centenário de Os Lusíadas, trad. de A. de A. Maia. Coimbra, Portugal: Livraria Almedina.

Gironella, J. M. (versión 2017, 1953). Los cipreses creen en Dios. Barcelona, España: Planeta.

Gironella, J. M. (1961). Un millón de muertos, 3aㅡ ed.. Barcelona, España: Planeta.

Gironella, J. M. (versión 2011, 1966). Ha estallado la paz. Barcelona, España: Planeta.

Gomes, M. E. R., Matos, M. M. de, Faria, A. M. L de e Pereira, J. M. (1986). História de Portugal. Lisboa, Portugal: Texto Editora.

Institute for economics \& peace. (2018). Global peace index 2018: Measuring peace in a complex world. Recuperado de: http://visionofhumanity.org/reports.

\section{(c) (i) (9) (2)}

La Revista Estudios es editada por la Universidad de Costa Rica y se distribuye bajo una Licencia Creative Commons Atribución-NoComercial-CompartirIgual 3.0 Costa Rica. Para más información envíe un mensaje a 
Dossier: Poesía, armonía y conflictos: ayer y hoy

Magalhães, G. (2014). Como sobreviver a Portugal continuando a ser português. Lisboa, Portugal: Planeta.

Martins, J. P. de O. (versión 1986, 1891). Camões: Os lusíadas e a renascença em Portugal. Lisboa, Portugal: Guimarães Editores.

Pérez Galdós, B. (versión 1996, 1873). Trafalgar, ed. de J. Rodríguez. Madrid, España: Cátedra.

Pérez Galdós, B. (versión 2001, 1876). Doña Perfecta, ed. de R. Cardona. Madrid, España: Cátedra.

Pérez Galdós, B. (versión 2011, 1876-1877). Gloria, ed. de I. J. López. Madrid, España: Cátedra.

Pérez Galdós, B. (versión 2002, 1878). Marianela, ed. de J. Casalduero. Madrid, España: Cátedra.

Pérez Galdós, B. (versión 2001, 1882). El amigo Manso, ed. de F. Caudet. Madrid, España: Cátedra.

Pérez Galdós, B. (versión 2001, 1887). Fortunata y Jacinta. Madrid, España: Edimat Libros.

Pérez Reverte, A. (versión 1998, 1996). El capitán Alatriste. Madrid, España: Alfaguara.

Pérez Reverte, A. (2004). Cabo Trafalgar. Madrid, España: Alfaguara.

Pessanha, C. (versión 1995, 1920). Clepsydra, ed. crítica de Paulo Franchetti. Lisboa, Portugal: Relógio d’Água.

Pessoa, F. (versión 1979, 1934). Mensagem. Lisboa, Portugal: Ática.

\section{(c) (i) (2) (2)}

La Revista Estudios es editada por la Universidad de Costa Rica y se distribuye bajo una Licencia Creative Commons Atribución-NoComercial-Compartirlgual 3.0 Costa Rica. Para más información envíe un mensaje a 
Dossier: Poesía, armonía y conflictos: ayer y hoy

Pessoa, F. (1981). Obra poética, trad. de Miguel Ángel Viqueira, 2 vols.. Sant Cugat del Vallès, España: Ediciones 29.

Ramalho, A. da C. (1992). Camões no seu tempo e no nosso. Coimbra, Portugal: Livraria Almedina.

Saraiva, A. J. (versión 1995, 1992). Estudos sobre a arte d'Os lusíadas. Lisboa, Portugal: Gradiva.

\footnotetext{
' Citaremos los versos de Os lusíadas indicando, entre paréntesis, el canto al que pertenecen, el número de la estrofa en que se integran y, finalmente, el número del verso en esa estrofa. De este modo, el lector podrá comprobar las citas en cualquier edición de esta obra.

ii Para una mejor comprensión del material citado, hemos actualizado la ortografía de los textos presentes en la edición crítica de Clepsydra, que es la que hemos manejado.

iii Para quien posea otra edición, distinta de la que hemos usado en este estudio, el discurso de D. Quijote sobre las armas y las letras se incluye en una parte del capítulo XXXVII y todo el capítulo XXXVIII de la primera parte de esta obra, publicada en 1605.
}

La Revista Estudios es editada por la Universidad de Costa Rica y se distribuye bajo una Licencia Creative Commons Atribución-NoComercial-CompartirIgual 3.0 Costa Rica. Para más información envíe un mensaje a revistaestudios.eeg@ucr.ac.cr. 